\title{
Correction to: Early outcomes of tapering jejunoplasty by antimesenteric seromuscular stripping and mucosal inversion for proximal jejunal atresia
}

\author{
Mahmoud Marei Marei ${ }^{1,2^{*}}$, Mohamed Hamed Abouelfadl', Ahmed Arafa Elsayed Rawwash', \\ Hamed Mahmoud Seleim ${ }^{1,3}$, Wesam Mohamed Mahmoud ${ }^{1}$, Tamer Yassin Mohamed Yassin ${ }^{1}$ and \\ Gamal Hassan El-Tagy ${ }^{1}$
}

\section{Correction to: Egypt Pediatric Association Gaz 67, 4 (2019) https://doi.org/10.1186/s43054-019-0003-9}

Following publication of the original article [1], the authors reported an error in the Background section.

The sentence currently reads:

With at least 1,300,00 live births per year in Egypt, about $400-500$ cases of jejunoileal atresia are being born yearly $[4,5]$.

The sentence should read:

With at least 2,300,000 live births per year in Egypt, about 400-700 cases of jejunoileal atresia are being born yearly $[4,5]$.

This has now been included in this correction article.

\section{Author details}

${ }^{1}$ Department of Surgery, Pediatric and Neonatal Surgery Unit, Cairo University Specialized Pediatric Hospital (CUSPH), Faculty of Medicine, Cairo University, Cairo, Egypt. ${ }^{2}$ The Royal Manchester Children's Hospital and Manchester Royal Infirmary, Manchester University NHS Foundation Trust, Oxford Road, M13 9WL Manchester, England, UK. ${ }^{3}$ Department of Pediatric Surgery, Tanta University Hospital, Faculty of Medicine, Tanta University, Tanta, Egypt.
Published online: 21 October 2020

\section{Reference}

1. Marei MM, Abouelfadl MH, Rawwash AAE et al (2019) Early outcomes of tapering jejunoplasty by antimesenteric seromuscular stripping and mucosal inversion for proximal jejunal atresia. Egypt Pediatric Association Gaz 67:4 https://doi.org/10.1186/s43054-019-0003-9

The original article can be found online at https://doi.org/10.1186/s43054019-0003-9.

* Correspondence: m.marei@kasralainy.edu.eg; m.marei@nhs.net

'Department of Surgery, Pediatric and Neonatal Surgery Unit, Cairo

University Specialized Pediatric Hospital (CUSPH), Faculty of Medicine, Cairo University, Cairo, Egypt

${ }^{2}$ The Royal Manchester Children's Hospital and Manchester Royal Infirmary, Manchester University NHS Foundation Trust, Oxford Road, M13 9WL

Manchester, England, UK

Full list of author information is available at the end of the article

Springer Open

(c) The Author(s). 2020 Open Access This article is licensed under a Creative Commons Attribution 4.0 International License which permits use, sharing, adaptation, distribution and reproduction in any medium or format, as long as you give appropriate credit to the original author(s) and the source, provide a link to the Creative Commons licence, and indicate if changes were made. The images or other third party material in this article are included in the article's Creative Commons licence, unless indicated otherwise in a credit line to the material. If material is not included in the article's Creative Commons licence and your intended use is not permitted by statutory regulation or exceeds the permitted use, you will need to obtain permission directly from the copyright holder. To view a copy of this licence, visit http://creativecommons.org/licenses/by/4.0/. 